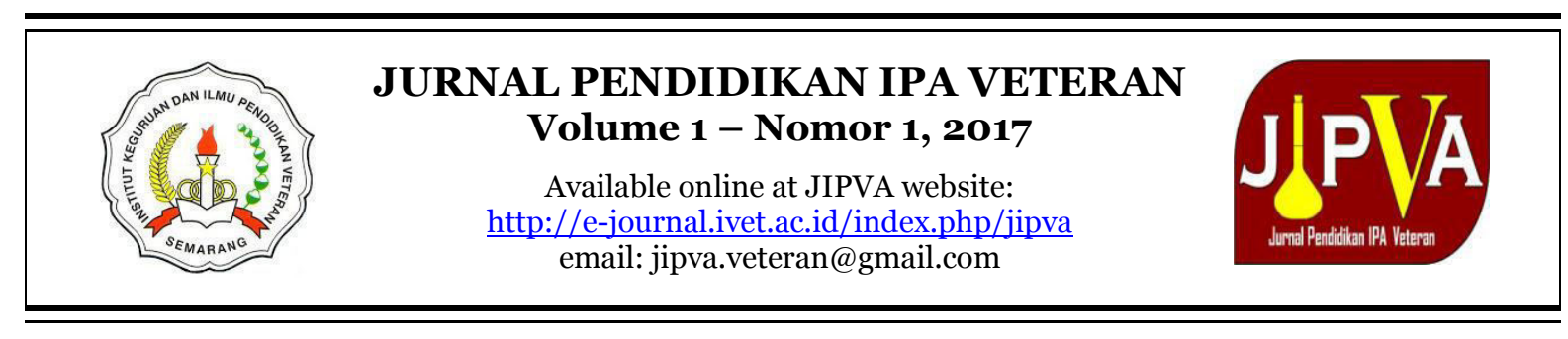

\title{
MISKONSEPSI MAHASISWA TEKNIK INFORMATIKA PADA MATERI KELISTRIKAN
}

\author{
Rizki Noor Prasetyono \\ Dosen Fakultas Sains dan Teknologi Universitas Peradaban Bumiayu \\ Email: pr45t91@gmail.com
}

\begin{abstract}
Abstrak
Penelitian ini bertujuan untuk mengetahui kedalaman mahasiswa dalam memahami konsep kelistrikan dan miskonsepsi yang dialami. Penelitian ini dilaksanalan sebelum perkuliahan mata kuliah Fisika Dasar II pada mahasiswa teknik informatika tahun ajaran 2016/2017. Untuk mengidentifikasi pra konsepsi dan miskonsepsi mahasiswa pada materi kelistrikan digunakan instrument tes pilihan ganda dengan metode Certain of Response Index. Metode ini juga dapat membedakan jawaban dari pertanyaan mahasiswa yang mengalami miskonsepsi, keberuntungan menjawab (lucky guess), kurangnya pengetahuan (lack of knowledge), dan mahasiswa yang memahami materi. Berdasarkan data hasil penelitian didapatkan lima pertanyaan dari konsep dasar kelistrikan bahwa mahasiswa mengalami miskonsepsi. Mahasiswa mengalami miskonsepsi pada konsep arus listrik, tegangan dalam rangkaian, penerapan hukum ohm, hambatan variabel, dan penerapan hukum kirchoff. Berdasarkan lima butir soal pada materi kelistrikan, $71 \%$ mahasiswa mengalami miskonsepsi.
\end{abstract}

Kata kunci: Miskonsepsi, CRI, Kelistrikan

\section{MISCONSEPS STUDENTS OF INFORMATIC ENGINEERING IN ELECTRICAL SUBJECT}

\begin{abstract}
The purpose of the research was find the depth of students in understand the electrical concepts and misconceptions experienced. This research was conducted before the subject of Physics II course in Informatics Engineering students of the academic year 2016/2017. To identify the preconceptions and misconceptions students of electrical subject used multiplechoice test instrument with the method Certain of Response Index. This method can also distinguish answers from students who have misconception, lucky guess answer, lack of knowledge, and students who understand the material. Based on the research data, the five questions of the basic concepts of electricity college students have misconceptions. Students have misconceptions on the concept of electric current, voltage in the circuit, the application of ohms law, variable resistor, and the application of Kirchhoff laws.Based on five quetions electrical materials, $71 \%$ of students has misconceptions
\end{abstract}

Keywords: Misconceptions, Certain of Response Index, electrical concepts 


\section{PENDAHULUAN}

Standar Nasional Pendidikan Tinggi (SNPT) tahun 2015 setiap perguruan tinggi negeri dan swasta harus memiliki capaian pembelajaran. Hal ini diatur dalam Permenristekdikti no. 44/2015 dimana setiap perguruan tinggi memiliki capaian pembelajaran yang memuat sikap (afeksi), penguasaan pengetahuan (kognitif), kemampuan kerja keterampilan umum dan khusus (psikomotorik) diuraikan dalam capaian pembelajaran umum, khusus dan capaian pembelajaran penciri perguruan tinggi. Penguasaan pengetahuan ini harus dimiliki mahasiswa setelah melakukan perkuliahan sebagai salah satu tolak ukur capaian pembelajaran. Maka dari itu penguasaan pengetahuan tersebut tidak boleh menyimpangataupun salah dalam penguasaan konsep dan aplikasinya.

Mahasiswa teknik informatika harus memiliki konsep dasar kelistrikan agar mampu dalam praktik dan kerja di lapangan dalam bidang teknologi informasi dan komputer. Selain pehaman konsep juga terbentuk berpikir secara logis, sistematis, objektif, jujur, dan disiplin. Pembangunan konsep dasar dari kelistrikan seharusnya sudah dialami mahasiswa ketika mereka belajar pada tingkat pendidikan sebelum masuk perguruan tinggi dalam pembelajaran IPA ataupun Fisika. Menurut Janulis dan Ganti (2008) dari pengalaman dan pengetahuan mahasiswa mengenai konsep kelistrikan itu kemudian terbentuk pemahaman dari teori yang pernah dialami mahasiswa tentang konsep tersebut. Pemahaman dari pengetahuan yang lebih lanjut dapat menimbulkan intuisi dari mahasiswa sendiri tentang peristiwa kelistrikan padahal belum tentu kebenaranya.
Rizki Noor Prasetyono

Intuisi teori pada mahasiswa tersebut dapat menimbulkan miskonsepsi. Miskonsepsi pada dasarnya merupakan kesalahan atau penyimpangan yang timbul dari konsep yang seharusnya dan kesepakatan para ahli di bidangnya (Berg, 1991). Mahasiswa menganggap intuisi atau paham konsep yang dulu pernah didapatkan sebagai solusi bagi permasalahan yang terjadi dalam kehidupan sehari-hari. Menurut Hasan, dkk (1999) bahwa miskonsepsi muncul dapat disebabkan karena perbedaan struktur konsep dari para ahli dan konsep sebenarnya kemudian dapat disebabkan karena kepercayaan dari konsep yang lama sebelum muncul konsep dan pengetahuan yang terbaru. Jadi asumsi yang muncul tersebut dapat disebut dengan prekonsepsi atau alternatif konsep yang merupakan bagian dari miskonsepsi.

Pembelajaran fisika khususnya kelistrikan memiliki keterkaitan antara satu konsep dasar dengan konsep dasar lainya. Menurut Katu dalam Zainuddin (2006) Terbatasnya informasi yang didapat dan terbatasnya akan pembuktian dalam konsepsi yang dibangun bisa menyebabkan timbulnya miskonsepsi juga. Kerangka berpikir yang melalui asumsi sementara tanpa ada pembuktian konsep lebih lanjut dan informasi yang lengkap menyebabkan kesulitan dalam menerima pengetahuan yang lebih tepat dan benar. Sebelum terbukti mengalami miskonsepsi mahasiswa akan konsisten dengan asumsi dan intuisi konsep yang dimilikinya.

Pemahaman yang mentah atau alternatif konsep yang dimiliki menjadikan mahasiswa kesulitan dalam menerima konsep yang sebenarnya ataupun konsep yang baru. Maka diperlukan identifikasi miskonsepsi untuk mengetahui bahwa 
mahasiswa memiliki kelemahan ataupun penyimpangan dalam pemahaman konsep. Berdasarkan hal tersebut dapat diselesaikan dengan memberikan metode atau program pembelajaran yang sesuai. Penelitian yang relevan dengan miskonsepsi yaitu Thohir, dkk (2013) menjelaskan bahwa identifikasi yang dilakukan pada mahasiswa pendidikan Fisika dibutuhkan untuk menentukan mahasiswa mengalami miskonsepsi kemudian dilakukan perlakuan dengan pembelajaran penemuan terbimbing dengan meningkatkan keterampilan berpikir kritis. Eka Putra (2016) menyatakan bahwa dengan menggunakan media pembelajaran Lectora Inspie dengan simulasi berbasis PhET mampu meremidiasi miskonsepsi pada pemahaman konsep listrik dinamis.

Penanganan dalam usaha meminimalkan miskonsepsi juga dilakukan dalam penelitian Suhandi, dkk (2009) bahwa menggunakan media simulasi virtual dengan pendekatan pembelajaran konseptual interaktif mampu meningkatkan efektifitas dalam pembelajaran. Media simulasi virtual ini mampu digunakan dalam pembelajaran sebagai sarana memperdalam penjelasan dengan demonstrasi. Penelitian Sendy dan Budi (2014) mendefinisikan dengan menggunakan pembelajaran inkuiri terbimbing mampu mengurangi miskonsepsi pada siswa.

Miskonsepsi dapat diketahui dengan beberapa cara salah satunya yang lebih mudah dan efisien yaitu dengan menggunakan tes diagnostik (Berg, 1991). Tes diagnostik ini dapat dilakukan sebelum melakukan pembelajaran biasanya digunakan untuk mengetahui kelemahan pemahaman konsep sehingga kelemahan tersebut dapat diatasi dengan perlakuan yang tepat (Arikunto, 2006).
Penggunaan instrumen tes untuk mengidentifikasi miskonsepsi salah satunya dengan menggunakan Certainty of Response Indeks. Tes ini merupakan tes pilihan ganda yang dilengkapi dengan respon keyakinan dengan menggunakan skala keyakinan. Menurut Hasan, dkk (1999) analisis CRI ini dapat untuk mengidentifikasi ataupun mengetahui mahasiswa yang mengalami miskonsepsi, mahasiswa yang paham konsep, dan mahasiswa yang tidak paham konsep sama sekali berdasarkan jawaban tes dan respon CRI yang didapat.

Ujian akhir semester dapat digunakan sebagai tolak ukur pemahaman mahasiswa tentang penguasaan konsep. Nilai UAS yang didapatkan dalam perkuliahan fisika dasar I mahasiswa teknik informatika dalam persentase yaitu $10 \%$ untuk mahasiswa yang mendapatkan nilai $80-100,50 \%$ untuk mahasiswa yang mendapatkan nilai 66-79, dan $40 \%$ untuk mahasiswa yang mendapatkan nilai 50-65\%. Hal ini menunjukan $40 \%$ mahasiswa yang mendapatkan nilai tersebut masih belum pemahaman konsep dengan baik. Kesulitan tersebut dapat terjadi salah satunya karena terjadi miskonsepsi. Menurut Rusilowati (2006) ketika seseorang mengalami miskonsepsi dapat terbawa kejenjang berikutnya.

Berdasarkan kenyataan tersebut dibutuhkan identifikasi miskonsepsi pada materi kelistrikan pada mahasiswa teknik informatika.

\section{METODE PENELITIAN}

Penelitian ini merupakan penelitian ekploratif deskriptif dimaksudkan untuk mengidentifikasi, mendeskripsikan, dan mengumpulkan informasi mengenai keadaan gejala dalam hal ini adalah miskonsepsi mahasiswa pada materi kelistrikan. 
Penelitian ini diadakan di fakultas sains dan teknologi program studi teknik informatika Universitas Peradaban Bumiayu. Subjek penelitian sebanyak 20 mahasiswa teknik informatika tahun ajaran 2016-2017 semester genap yang belum mengikuti mata kuliah fisika dasar II. Alur penelitian yang dilakukan pada gambar 1 .

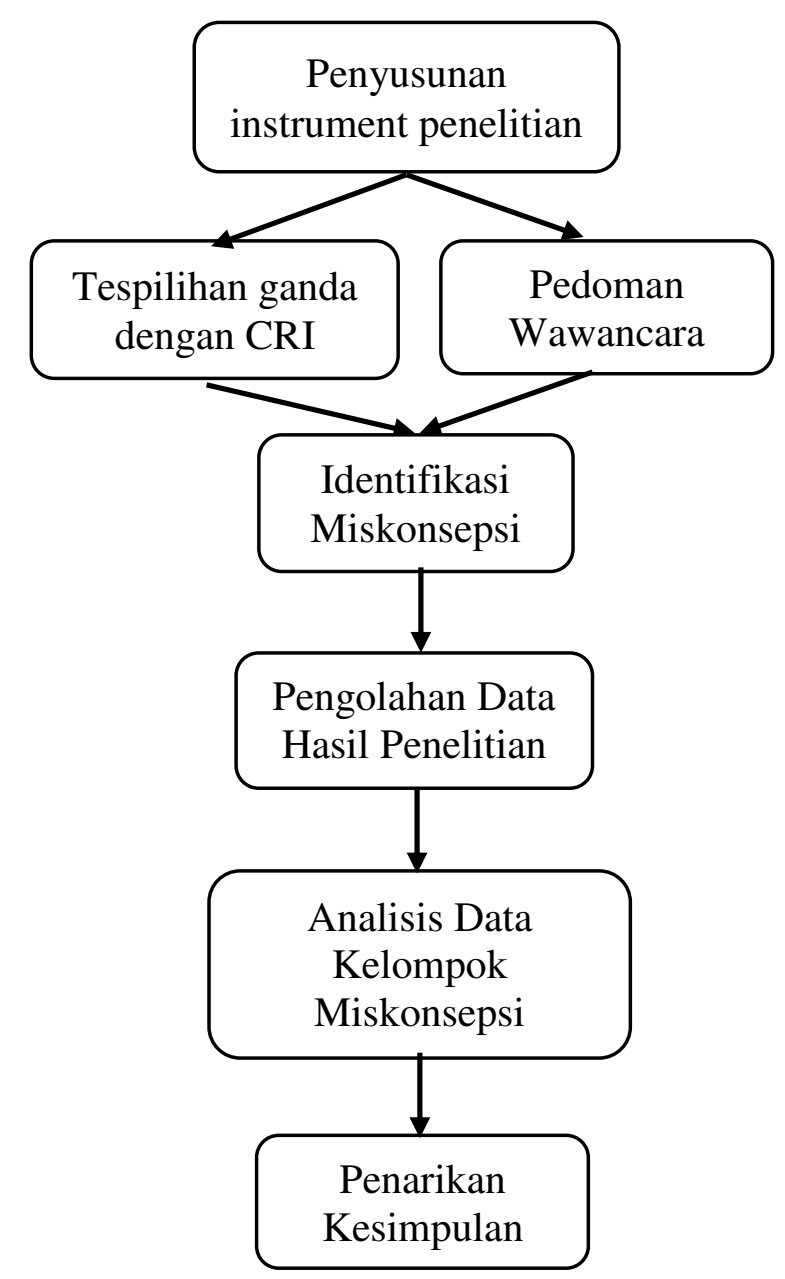

Gambar 1. Alurpenelitian

Penelitian ini dimaksudkan untuk mengidentifikasi miskonsepsi kelistrikan dengan menggunakan teknik pengumpulan data yaitu tes pilihan ganda dalam model CRI (Certain of Respose Index) dan wawancara secara langsung. Instrument tes CRI diuji coba pada mahasiswa semester 4 teknik informatika yang sudah menempuh mata kuliah fisika dasar I dan II. Mahasiswa
Rizki Noor Prasetyono

yang melakukan uji coba instrument tes sebanyak 25 orang. Uji coba instrument tes dilakukan untuk mengetahui validitas dan realibilitas. Analisis data validitas dan reblitas tes menggunakan Microsoft excel.

Tes pilihan ganda dengan CRI untuk mengidentifikasi miskonsepsi dengan mencari jawaban benar dan jawaban salah pada materi kelistrikan menggunakan persamaan berikut:

$$
\begin{aligned}
& R_{b}=\frac{\sum C R I_{b}}{n_{b}} \text { dan } \\
& R_{s}=\frac{\sum C R I_{s}}{n_{s}}
\end{aligned}
$$

Keterangan :

$R b \quad=$ rata-rata CRI untuk jawaban benar $\sum C R I_{b}=$ jumlah nilai CRI jawaban benar $n_{b} \quad=$ jumlah mahasiswa yang menjawab benar

$R s \quad=$ rata-rata CRI untuk jawaban salah

$\sum C R I_{S}=$ jumlah nilai CRI jawaban salah

$n_{s} \quad=$ jumlah mahasiswa yang menjawab salah

Menentukan fraksi mahasiswa yang menjawab benar dari total seluruh mahasiswa, menggunakan persamaan berikut:

$$
f_{b}=\frac{n_{b}}{T}
$$

Keterangan :

$f_{b} \quad=$ fraksi yang menjawab benar

$n_{b} \quad=$ jumlah mahasiswa yang menjawab benar

$T \quad=$ jumlah total mahasiswa

Kemudian tiap butir soal dilakukan persentase untuk mengetahui jumlah mahasiswa menjawab benar dengan menggunakan persamaan berikut ini:

$$
\text { Persentase }(\%)=\frac{n_{b}}{T} \times 100 \%
$$


Keterangan :

$n_{b} \quad=$ jumlah mahasiswa yang menjawab benar

$T \quad=$ jumlah total siswa

Dengan penggunaan metode CRI ini mahasiswa akan memberikan respon dari jawabannya. Rentang skala yang digunakan adalah skala 6 sebagai berikut, (0) untuk jawaban yang hanya ditebak saja (totally guessed answer), (1) untuk jawaban yang hampir ditebak (almost a guess), (2) untuk jawaban yang tidak yakin (not sure), (3) untuk jawaban yakin (sure), (4) untuk jawaban yang mendekati benar (almost certain), dan (5) untuk jawaban pasti benar (certain) (Hasan dkk, 1991). Kemudian ditentukan mahasiswa yang mengalami miskonsepsi dari Tabel 1 berikut ini :

Tabel 1. Matriks Penentuan Mahasiswa yang Mengalami Miskonsepsi

\begin{tabular}{llll}
\hline Tipe & CRI Rendah $<$ & CRI Tinggi > \\
Jawaban & $\mathbf{2 . 5}$ & $\mathbf{2 . 5}$ \\
\hline Jawaban & Jumlah & Jumlah \\
Benar & jawaban benar & jawaban benar \\
& dan & CRI & dan CRI tinggi. \\
& rendah. & \\
& kategori & Kategori \\
& keberuntungan & paham konsep \\
& menebak (lucky & yang benar \\
& guess) &
\end{tabular}

\begin{tabular}{llll}
\hline Jawaban & Jumlah & Jumlah \\
Salah & jawaban yang & jawaban yang \\
& salah dan CRI & salah dan CRI \\
& rendah. & tinggi. \\
& kategori tidak & Kategori \\
& mengerti sama & Miskonsepsi \\
& sekali (lack of & \\
& knowledge) & \\
\hline
\end{tabular}

Kemudian wawancara dibuat

pedoman berdasarkan respons keyakinan mahasiswa dalam menjawab tes kemudian mengetahui konsistensi dari mahasiswa. Wawancara ini dimaksudkan untuk mengetahui alasan yang lebih dalam bagaimana mahasiswa mengeluarkan pendapat tentang keputusannya dalam memberikan pilihan pada tes.

\section{HASIL DAN PEMBAHASAN}

Hasil uji coba instrument tes didapakan nilai validitas dan reliabilitas pada data Tabel 2 sebagai berikut :

Tabel 2 Nilai Validitas dan Reliabilitas

No Validitas Kategori Reliabiltas Kategori

\begin{tabular}{ccccl}
\hline 1 & 0.517 & valid & 0.62 & reliabel \\
\hline 2 & 0.561 & valid & 0.62 & reliabel \\
\hline 3 & 0.467 & valid & 0.78 & reliabel \\
\hline 4 & 0.607 & valid & 0.92 & reliabel \\
\hline 5 & 0.455 & valid & 0.21 & $\begin{array}{l}\text { tidak } \\
\text { reliabel }\end{array}$ \\
\hline 6 & 0.089 & Drop & 0.25 & $\begin{array}{l}\text { tidak } \\
\text { reliabel }\end{array}$ \\
\hline 7 & 0.443 & valid & 0.85 & reliabel \\
\hline 8 & 0.657 & valid & 0.84 & reliabel \\
\hline 9 & -0.094 & Drop & 0.11 & $\begin{array}{l}\text { tidak } \\
\text { reliabel }\end{array}$ \\
\hline 10 & 0.464 & valid & 0.84 & reliabel \\
\hline 11 & 0.483 & valid & 0.76 & reliabel \\
\hline 12 & -0.193 & drop & 0.11 & $\begin{array}{l}\text { tidak } \\
\text { reliabel }\end{array}$ \\
\hline 13 & 0.494 & valid & 0.56 & reliabel \\
\hline 14 & 0.168 & drop & 0.86 & reliabel \\
\hline 15 & -0.135 & drop & 0.76 & reliabel \\
\hline 16 & 0.474 & valid & 0.72 & reliabel \\
\hline 17 & 0.067 & drop & -0.13 & $\begin{array}{l}\text { tidak } \\
\text { reliabel }\end{array}$ \\
\hline 18 & 0.487 & valid & 0.78 & reliabel \\
\hline 19 & -0.298 & drop & 0.29 & $\begin{array}{l}\text { tidak } \\
\text { reliabel }\end{array}$ \\
\hline 20 & 0.574 & valid & 0.86 & reliabel \\
\hline 21 & 0.494 & valid & 0.86 & reliabel \\
\hline 22 & -0.165 & drop & 0.76 & reliabel \\
\hline 25 & 0.245 & drop & 0.15 & $\begin{array}{l}\text { tidak } \\
\text { reliabel }\end{array}$ \\
\hline & 0.678 & valid & 0.65 & reliabel \\
\hline Berdasarkan & Tabel & 2 & menunjukan \\
\hline
\end{tabular}

didapatkan data 9 butir soal memiki kategori tidak valid/ drop yaitu nomor 6, 9, 12, 
14,15, 17, 19, 22, dan 23. Kesembilan nomer tersebut tidak memenuhi kriteria valid karena $r$ hitung $<\mathrm{r}$ tabel dimana harga $r$ tabel $=0,396$. Harga $r$ tabel ditentukan dari $r$ produk momen pada tabel dengan taraf signifikasni $5 \%(0,05)$.

Sesuai dengan Tabel 2 hasil perhitungan reliabiltas didapatkan data 7 butir soal yang tidak memenuhi kreteria reliabel yaitu nomor $5,6,9,12,17,19$, dan 23. Ketujuh butir soal tersebut tidak reliablitas dikarenakan $\mathrm{r}$ hitung $<\mathrm{r}$ tabel dimana harga untuk $r$ tabel $=0,396$.

Berdasarkan hasil data perhitungan validitas dan relibilitas didapatkan 15 butir soal yang memenuhi standar valid dan reliabel. Soal no 5 tidak digunakan karena butir soal tidak memenuhi kriteria realibilitas walaupun memenuhi kriteria valid. Butir soal yang digunakan adalah 1,2 , $3,4,7,8,10,11,13,16,18,20,21,24$, dan 25 .

Penyusunan tes identifikasi miskonsepsi dengan CRI ini berdasakan konsep dasar kelistrikan dengan sub konsep pada Tabel 3.

Tabel 3. Sub Konsep Pada Tiap Butir Soal

\begin{tabular}{ll}
\hline Sub Konsep & No Butir Soal \\
\hline Kuat arus & 1 dan 3 \\
Tegangan & 2 \\
Penerapan Hukum Ohm & 4,5 , dan 6 \\
Hambatan & 7,8 , dan 9 \\
Hukum I Kirchoff & 10 , dan 13 \\
Rangkaian Hambatan Seri & 11 , dan 12 \\
dan Paralel & \\
Hukum II Kirchoff & 15 \\
Daya Listrik & 14 \\
\hline
\end{tabular}

Berdasarkan analisis data penelitian menggunakan instrumen tes pilihan ganda
Rizki Noor Prasetyono

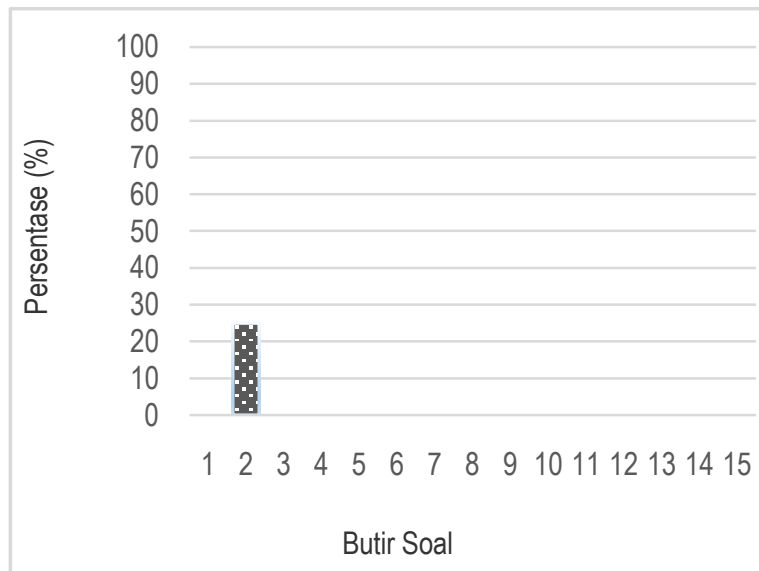

dengan CRI didapatkan hasil penelitian yang dijelaskan pada Gambar 2.

Gambar. 2 Persentase mahasiswa menjawab benar tiap butir soal

Berdasarkan Gambar 2 didapatkan persentase nilai tertinggi dari butir soal nomor 7 yaitu $90 \%$ menjawab benar. Pada sub konsep hambatan untuk butir soal nomor 7 lebih banyak mahasiswa yang memahaminya. Nilai terendah terdapat pada butir soal nomor 1 didapatkan persentase 20 $\%$ siswa menjawab benar. Berarti pada sub konsep kuat arus butir soal nomor 1 kurang dipahami mahasiswa.

Berdasakan data pada gambar 2 butir soal nomor $2,4,6,8,10,12,13$, dan 15 banyaknya mahasiswa menjawab benar di bawah 60\%. Sebagian besar mahasiswa mengalami kesulitan dalam butir soal tersebut. Data tersebut dianalisis untuk mengetahui miskonsepsi yang terjadi.

Berdasarkan hasil pengambilan data dari tes diagnostik sebelum melalui perkuliahan fisika dasar II dan konsep kelistrikan dengan CRI didapatkan data pada Gambar 3. 


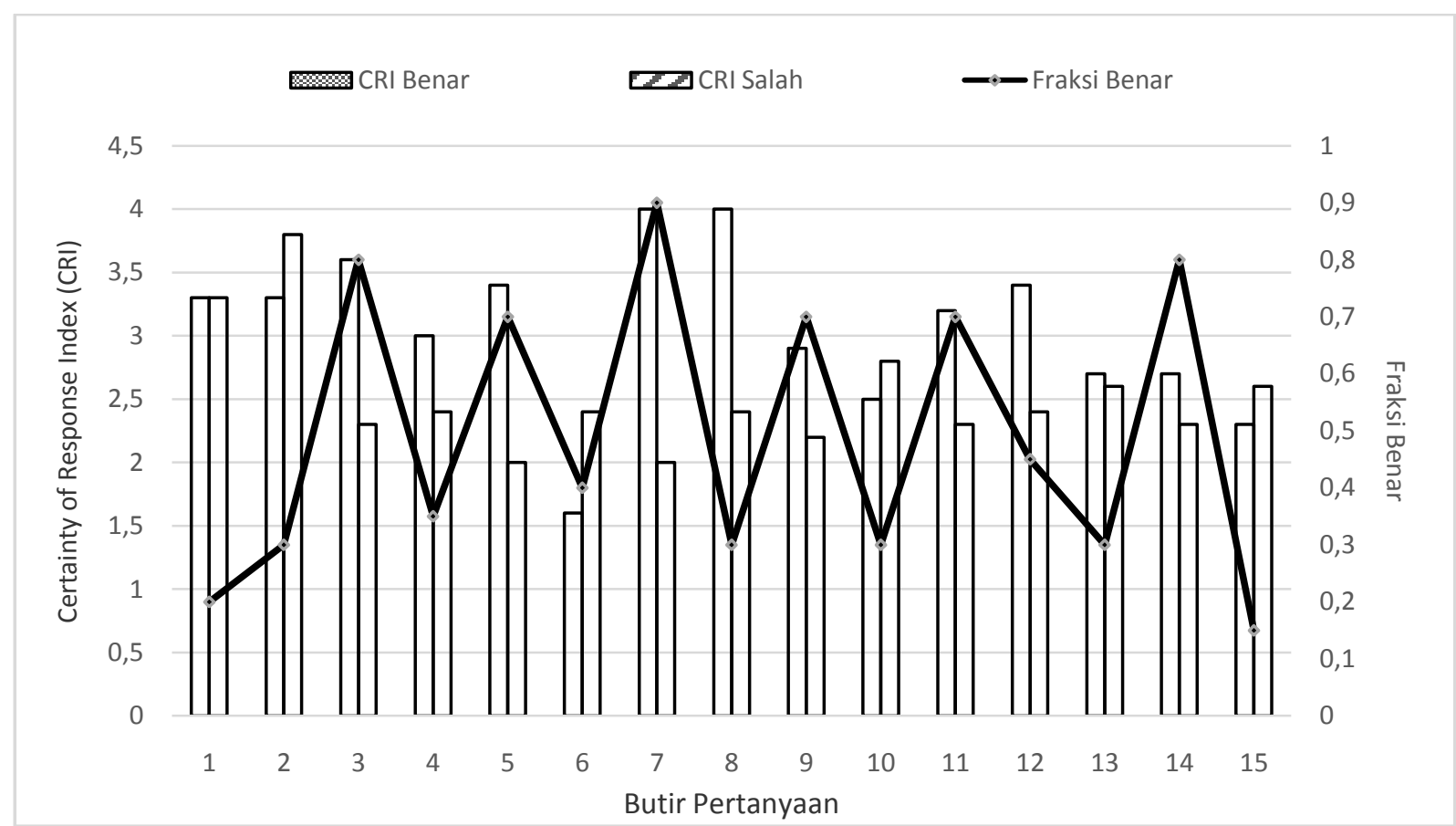

Gambar 3. Rata- rata nilai jawaban CRI benar dan salah dari setiap butir pertanyaan.

Berdasarkan Gambar 3 dari butir soal nomor 1, 2, 6, 8 dan 13 didapatkan bahwa data tersebut terindikasi banyak mahasiswa mengalami miskonsepsi. Pada butir soal nomor 1 CRI dari jawaban benar yaitu 3,3 dan CRI jawaban salah 3,3 dengan fraksi jawaban benar 0,2. Berdasarkan Gambar 3. $80 \%$ mahasiswa menjawab salah ditunjukan fraksi jawaban yang sedikit yaitu 0,2 akan tetapi memiliki CRI tinggi sehingga terindikasi miskonsepsi.

Hal tersebut diperkuat dengan hasil wawancara pada butir soal nomor 1 mahasiswa menganggap arus listrik yang bergerak adalah muatan proton yang berasal dari kutub positif karena arah arus bergerak dari kutub positif ke kutub negatif. Asumsi ini merupakan kesimpulan yang mereka dapat dari pengetahuan mereka sebelumnya. Konsepsi seperti ini merupakan miskonsepsi seharusnya muatan yang bergerak adalah elektron bukan proton, konsep arus listrik merupakan arus konvensional/ kesepakatan para ahli.
Penelitian Zainudin (2006) juga menyatakan bahwa pada konsep dasar arus listrik mengenai muatan yang bergerak, terdapat 50 mahasiswa program studi jurusan fisika mengalami miskonsepsi. Hal ini menunjukan pada konsep ini mahasiswa mengalami miskonsepsi, terjebak dengan asumsi sementara dengan mendapatkan informasi yang kurang lengkap.

Pada butir soal nomor 2 hampir sama dengan butir soal nomor 1 dengan nilai CRI jawaban benar dan salah diatas 2,5 sesuai dengan gambar 2. dengan fraksi jawaban benar 0,3 terindikasi miskonsepsi. Hal ini diperkuat dengan hasil wawancara pada butir soal nomor 2 mengenai sumber tegangan searah (DC) pada rangkaian listrik, mahasiswa menyatakan bahwa ketika dua buah sumber tegangan DC jika dirangkaikan secara paralel kemudian dihubungkan ke lampu maka nyala lampu akan bertambah terang dari pada menggunakan satu sumber tegangan. 
Rizki Noor Prasetyono

Butir soal nomor 13 didapatkan data penelitian CRI jawaban benar yaitu 2,7 dan CRI jawaban salah yaitu 2,6 dari gambar 2 dengan fraksi jawaban benar sebesar 0,3 maka diidentifkasi sebagai miskonsepsi. Butir soal nomor 13 ini mengenai hukum I Kirchoff. Berdasarkan hasil wawancara mahasiswa menganggap arus yang masuk pada titik percabangan berbeda nilainya dengan arus yang keluar dari titik percabangan. Hampir sama kasusnya dengan butir soal nomor 8 mahasiswa mengasumsikan bahwa arus masuk tidak sama dengan arus keluar. Hal ini dikarenakan arus ada yang hilang ketika masuk dalam percabangan dari sebuah rangkaian. Miskonsepsi ini terjadi karena mahasiswa menerima informasi yang sebagian ataupun kurang lengkap.

Data butir soal nomor 3, 5, 7, 9, 11, dan 14 dikategorikan bukan miskonsepsi. Sesuai dengan gambar 2 dari fraksi jawaban benar dari butir soal nomor 3, 5, 7, 9, 11, dan 14 yaitu 0,$88 ; 0,77 ; 0,9 ; 0,7 ; 0,7$ dan 0,8 hal ini menunjukan sebagaian besar mahasiswa dapat manjawab butir soal tersebut. Hanya sebagian kecil dari mahasiswa yang kesulitan dalam menjawab butir soal tersebut. Diperkuat dengan ratarata CRI jawaban salah yang relatif kecil dibawah 2,5.

Berdasarkan gambar 2 menunjukan butir soal nomor $3,5,7,9,11$, dan 14 memiliki persentase mahasiswa menjawab benar di atas $60 \%$. Hal ini menunjukan $60 \%$ mahasiswa memahami konsep tersebut. Jadi untuk butir soal nomor 3, 5, 7, 9, 11, dan 14 sesuai dengan gambar 2 dikategorikan sebagai paham konsep yang benar.

Data dari butir soal nomor 4, 10, 12, dan 15 dikategorikan bukan miskonsepsi karena sesuai dengan gambar 2 ini rendahnya rata-rata CRI dari jawaban yang salah. Hal ini mengindikasikan bahwa mahasiswa lebih tidak paham konsep atau kurang pengetahuan tentang konsep dari butir soal tersebut. Berdasarkan data butir soal tersebut untuk CRI jawaban salah yang mendekati 2,5 diklasifikasikan CRI tingkat rendah walaupun CRI jawaban benar bernilai di atas 2,5 tetap dikategorikan CRI tinggkat rendah karena fraksi jawaban benar yang sedikit.

Keseluruhan butir soal merupakan konsep dasar dari kelistrikan, yaitu lima dari keseluruhan butir soal mengalami miskonsepsi. Harus ada antisipasi untuk masalah miskonsepsi karena kebiasaan mahasiswa yang mengalami miskonsepsi akan sulit dihilangkan sebelum diberikan perlakuan yang tepat. Menurut Hasan dkk (1999) seseorang yang tidak tahu konsep dapat diajarkan dengan lebih mudah dari pada miskonsepsi. Karena miskonsepsi bersifat tidak disadari, menghambat untuk percaya dengan pengetahuan dan informasi yang baru. Miskonsepsi harus diatasi dengan perlakuan yang terstruktur, berulang dan dilakukan pembuktian secara ilmiah, agar dapat diterima logika yang terindikasi miskonsepsi.

Materi Fisika dalam hal ini kelistrikan semua konsepnya saling berkaitan satu sama lain. Mulai dari konsep dasar dan turunanya harus dipahami dan diketahui oleh mahasiswa. Apabila konsep dasar yang dimiliki mahasiswa mengalami miskonsepsi akan lebih sulit dalam memahami materi selanjutnya. Menurut Zainudin (2006) kurang lengkapnya informasi dan ilmu pengetahuan mahasiswa memunculkan miskonsepsi. Materi yang abstrak dan kompleks menjadikan mahasiswa kesulitan memahami. Jika tidak diatasi maka bisa memunculkan pra 
konsepsi yang baru dan tidak beraturan dalam pemikiran mahasiswa.

Miskonsepsi ini dapat diatasi diantaranya dengan menggunakan metode, model, media ataupun alat peraga yang tepat dalam menjelaskan materi yang mengalami miskonsepsi tersebut. Sesuai dengan penelitian Thohir, dkk (2013) dengan metode penemuan terbimbing dalam peningkatan keterampilan berpikir kritis mampu mengurangi miskonsepsi dalam materi listrik dinamis. Pada penelitian Eka Putra, dkk (2016) juga menyatakan bahwa dengan media pembelajaran Lectora Inspire dan dengan bantuan simulasi berbasis PhET dapat mengurangi kuantitas miskonsepsi kemudian meningkatkan pemahaman konsep siswa pada materi konsep listrik dinamis.

Hasan, dkk (1999) menyatakan bahwa metode tes dengan CRI yang berguna untuk membuktikan pemahaman tiap indikator dan miskonsepsi yang dialami. Kemudian dari pertanyaan tersebut dapat diketahui kedalaman pemahaman dalam suatu materi. Pada identifikasi miskonsepsi penelitian ini dapat dikatakan $71 \%$ mahasiswa mengalami miskonsepsi. Kemudian dilakukan penanganan pada mahasiswa yang mengalami miskonsepsi dengan cara memberikan materi dan pembelajaran menggunakan metode, model atau media untuk menujukan teori yang benar. Pembelajaran yang mendorong mahasiswa dalam mencari alternatif penjelasan, konstruktifisme, dan pembuktian dalam percobaan dapat memberikan pengalaman yang membekas bagi mahasiswa.

\section{SIMPULAN DAN SARAN}

Berdasarkan hasil dan pembahasan dapat disimpulkan bahwa mahasiswa teknik informatika mengalami miskonsepsi pada konsep dasar kelistrikan yang ditunjukan pada butir soal nomor 1 sub kunsep kuat arus, nomor 2 sub konsep tegangan, nomor 6 sub konsep penerapan hukum ohm, nomor 8 sub konsep hambatan dan nomor 13 sub konsep hukum I Kirchoff. Agar miskonsepsi tersebut tidak semakin kuat, penemuan miskonsepsi ini harus ditangani dengan proses pembelajaran. Pembelajaran yang mendorong mahasiswa dalam mencari alternatif penjelasan, konstruktifisme, dan pembuktian dalam percobaan bisa memberi pengalaman yang membekas bagi mahasiswa.

\section{DAFTAR PUSTAKA}

Arikunto, suharsimi. (2006). Dasar-dasar Evaluasi Pendidikan (edisi revisi). Jakarta : Bumi Aksara

Berg, E.v.D.. (1991). Miskonsepsi Fisika dan Remidiasi. Salatiga: Universitas Kristen Satya Wacana

Eka Putra, Irsyaf., Adlim dan A.Halim. (2016). Analisis Miskonsepsi dan Upaya remidiasi Pembelajaran Listrik Dinamis dengan Menggunakan Media Pembelajaran Lectora Inspire dan PhET Simulation di SMAN Unggul Tunas Bangsa. Jurnal Pendidikan Sains Indonesia 4 (2). 13-19.

Hasan, Saleem., Diola Bagayoko., and Ella L Kelley. (1999). Misconceptions and the Certainty of Response Index (CRI). Journal of Physic Education 34 (5) 294-299.

Janulis P. Purba dan Ganti Depari. (2008). Penelusuran Miskonsepsi Mahasiswa Tentang Konsep Dalam Rangkaian Listrik Menggunakan Certainty of Response Index Dan Interview. Jurnal Pendidikan Teknik Elektro 1-19.

Katu. 1995. Konsepsi Awal dan Pengaruhnya Terhadap Pemahaman Mereka atas Konsep-konsep Sains yang diajarkan Guru.

Suhandi, Adi,. Parulian Sinaga,. Ida Kaniawati,. Dan Edi Sehendi. (2009). Efektifitas Penggunaan Media Simulasi Virtual pada Pendekatan 
Pembelajaran Konseptual Interaktif dlam Meningkatkan Pemahaman Konep dan Menimalkan Miskonsepsi. Jurnal Pengajaran MIPA 13 (1). 35-47

Sendy Zulia Witanecahya dan Budi Jatmiko (2014). Penerapan Model Pembelajran Inkuiri Terbimbing (Guided Inquiri) untuk Mengurangi Miskonsepsi Siswa Kelad X SMAN 2 Ponorogo pada Pokok Bahasan Perpindahan Panas. Jurnal Inovasi Pendidikan Fisika 03 (03). 6-10.

Rusilowati, Ani. (2006). Profil Kesulitan Belajar fisika Pokok Bahasan Kelistrikan Siswa SMA di Kota Semarang. Jurnal Pendidika Fisika Indonesia 4(2). 100-106.

Thohir, M. Anas, Wasis, Sugimin WW. (2013). Peningkatan Keterampilan Berpikir Kritis Melalui Pembelajaran Metode Penemuan Terbimbing dalam Upara Remidiasi Miskonsepsi Materi Listrik Dinamis. Jurnal Pendidikan Sains Pascasarjana Universitas Negeri Surabaya 1(2). 63-67.
Rizki Noor Prasetyono

Zainudin. (2006). Miskonsepsi Mahasiswa pada Materi Ajar Rangkaian Listrik Arus Searah. Jurnal Vidya Karya 24 (2). 113-117

\section{PROFIL SINGKAT}

Rizki Noor Prasetyono lahir di Brebes pada tanggal 11 Juli 1991; menempuh kuliah strata 1 di IKIP PGRI Semarang program studi pendidikan fisika lulus tahun 2012 kemudian melanjutkan gelar master (S2) di Universitas Negeri Semarang program studi pendidikan IPA konsentrasi pendidikan fisika lulus tahun 2016. Sekarang bekerja di Universitas Peradaban Bumiayu sebagai dosen Fakultas Sains dan Teknologi program studi Teknik Elektro. 